\title{
Fault Diagnosis Method of Permanent Magnet Synchronous Motor for Electrical Vehicle
}

\author{
Jin-Hyung Yoo and Tae-Uk Jung* \\ Kyungnam University, Changwon, Republic of Korea
}

(Received 10 June 2016, Received in final form 29 August 2016, Accepted 19 September 2016)

\begin{abstract}
The permanent magnet synchronous motor has high efficiency driving performance and high power density output characteristics compared with other motors. In addition, it has good regenerative operation characteristics during braking and deceleration driving condition. For this reason, permanent magnet synchronous motor is generally applied as a power train motor for electrical vehicle. In permanent magnet synchronous motor, the most probable causes of fault are demagnetization of rotor's permanent magnet and short of stator winding turn. Therefore, the demagnetization fault of permanent magnet and turn fault of stator winding should be detected quickly to reduce the risk of accident and to prevent the progress of breakdown of power train system. In this paper, the fault diagnosis method using high frequency low voltage injection was suggested to diagnose the demagnetization fault of rotor permanent magnet and the turn fault of stator winding. The proposed fault diagnosis method can be used to check the faults of permanent magnet synchronous motor during system check-up process at vehicle starting and idling stop mode. The feasibility and usefulness of the proposed method were verified by the finite element analysis.
\end{abstract}

Keywords : demagnetization fault, fault diagnosis, permanent magnet synchronous motor, turn fault

\section{Introduction}

In recent years, the market of electric vehicle (EV) has been expanded because it is more eco-friendly and efficient than conventional internal combustion engine vehicle. In $\mathrm{EV}$, an electrical motor instead of an engine is used for a power train to make propulsion power.

The permanent magnet synchronous motor (PMSM) having permanent magnets instead of field winding in the rotor has especially higher efficiency and power density characteristics than other types of motor. Furthermore, when the EV is braked and decelerated, the higher power regeneration operation is also possible than that of other motor due to permanent magnet (PM) of rotor. For this reason, PMSM is generally applied as power train motor for EVs.

In the application of EV, the reliability of power train motor is very important for the stability of vehicle. If the faults of power train motor are occurred, the passengers may be exposed to high risk of accident.

CThe Korean Magnetics Society. All rights reserved.

*Corresponding author: Tel: +82-55-249-2628

Fax: +82-505-999-2161, e-mail: tujung@kyungnam.ac.kr
In PMSM, the most probable causes of fault are the demagnetization of rotor's PM and the short of stator winding turns. Therefore, these faults should be monitored and detected quickly to reduce the risk of accident and to prevent the progress of breakdown of power train system.

The irreversible demagnetization of PM is a very severe fault of PMSM, it is caused by the phase switching error of drive inverter, overload current, and high temperature driving condition. The fault of stator winding is caused by the high insulation and the accumulated high voltage stress [1].

Several fault diagnosis methods for PMSM have been studied [2-7]. The general diagnosis methods are using the sensing waveforms and their spectrum analysis of the instantaneous voltage and current during the driving operation. In these methods, the sensing signal may contain large noise, and the sensing signal is varied with respect to the rotation speed and the load conditions.

Therefore, it takes a long calculation time, and the diagnosis equipment will be very complex. Besides, the simplest diagnosis method of rotor PM's demagnetization fault is to measure back EMF when the PMSM is in regenerative operation. However, this method has a draw- 
back to detect when demagnetization is not severe.

In this paper, the fault diagnosis method using high frequency low voltage (HFLV) injection method was suggested to diagnose demagnetization fault of rotor PM and turn fault of stator winding.

In this method, the high frequency and low voltage is injected to power train PMSM when the PMSM is standstill condition. The current waveforms of each phase are measured, and the frequency characteristics of current waveform are analyzed to diagnose the faults of PMSM.

The feasibility and usefulness of the proposed fault diagnosis method were verified by the FE analysis. The proposed method can be used to check the faults of PMSM during system check-up process at vehicle starting and idling stop mode.

\section{Failure mode of PMSM}

Faults of PMSM can be classified as electrical faults, magnetic faults and mechanical faults. In the electrical faults, the general faults are the short of stator winding turns and the demagnetization of rotor's PM. The turn fault of stator winding is a very usual electrical fault of electric motors including PMSM.

The fault of stator winding turn is caused by the high temperature rising of the overload condition, the breakdown of insulation and the accumulated high voltage stress. If this fault becomes worse to more bad condition without the fault detection and the timely shut down, it may cause demagnetization fault of rotor PM and fire of power train system after all.

Permanent magnets are one of the most important components in PMSM because it gives rotor fluxes in the airgap for the torque production. The PM can be demagnetized by the temperature variation and negative directional electromagnetic flux of stator. The reversible demagnetization is not a serious problem, but the irreversible demagnetization is a very serious fault of PMSM.
The irreversible demagnetization of PM is caused by the phase switching error of a drive inverter, the high overload current, and the high temperature driving condition. The PM's demagnetization faults are occurred partially or entirely in the rotor PM poles. Even if the partial demagnetization is occurred, it can be expanded to entire demagnetization rotor PMs and winding turn's fault.

These two faults, the demagnetization fault of PM and the winding turn's fault, are correlated each other. It means each fault may bring about the other fault.

There are various conventional diagnosis methods of motor classified and summarized as in Table 1.

The simplest diagnosis method for demagnetization fault of PM and turn fault is sensing back EMF (BEMF) during the regenerative braking operation. However, the BEMF characteristics can be varied with the temperature of PM, and this method is not capable to diagnose the partial demagnetization fault of PMs. Furthermore, it is very difficult to be applied for distributed winding type PMSM especially because of winding structure.

The other method is stator current frequency analysis method. It is a kind of on-line diagnosis method for PMSM. When the motor is operating, this method detects abnormal operation of PMSM by sensing of stator current and frequency analysis [2-4].

However, this method is not appropriate when the motor speed is frequently varied because the fundamental frequency of stator current is varied with motor speed. In addition, in many practical cases, limited on-board computational power severely restricts the use of these complex algorithms and associated optimization techniques.

Another diagnosis method is classified as parameter estimation methods. It is also a kind of on-line diagnosis method. When the motor is operating, this method diagnoses abnormal operation by sensing voltage, current of stator and the calculation of voltage equation of PMSM [5-7].

Fault current calculation using the sum of three phases

Table 1. Hardware Requirement and Drawbacks of Diagnosis Method.

\begin{tabular}{ccc}
\hline \hline Types of methods & Hardware requirement & Drawbacks \\
\hline BEMF monitoring & $\begin{array}{l}\text { Voltage sensor } \\
\text { Raster encoder } \\
\text { Current sensor, } \\
\text { Raster encoder } \\
\text { Voltage sensor }\end{array}$ & Hard to detect partial demagnetization and turn fault \\
Parameter estimation based on current and & Current sensor, & \\
voltage monitoring & Raster encoder & Accurate parameters of fault-free machine are required \\
Direct flux monitoring & Search coils, & Additional built-in flux sensors are required \\
& Raster encoder & Available for demagnetization fault only
\end{tabular}


current is a kind of parameter estimation method for turn fault detection. If the turn fault is occurred asymmetrically, turn fault can be detected by monitoring the sum of three phase current.

This diagnosis method requires accurately estimated parameters, e.g. resistance and inductance of stator winding and BEMF coefficient, of fault-free motor.

However, this method is difficult to be applied because the parameters are varied with load and temperature condition. Furthermore, this method may detect the abnormal operation of PMSM, but it is impossible to classify a failure mode of PMSM, whether the fault is turn fault or demagnetization fault of PM. In addition, this method also requires the high performance computation system configuration because of large computation burden due to complex algorithms and associated optimization techniques. Therefore, it is limited as an on-board computational system.

As a different diagnosis method, a direct flux monitoring method can detect the demagnetization fault of PM accurately, but it needs additional built-in flux sensors. This method can't detect the turn fault of stator winding and other types of faults also.

\section{Proposed Diagnosis Method}

In this paper, the target motor is selected as the power train PMSM of EV of KIA Motors, Korean automobile company. The specification of the target PMSM is as shown in Table 2. Rated output power is $30[\mathrm{~kW}]$, and neodymium rare earth PMs are applied in the rotor.

Figure 1 shows 2D FEA electromagnetic model and winding diagram of interior permanent magnet synchronous motor (IPMSM) of the target model. The winding configuration is single layer concentrated winding structure.

HFLV injection method is proposed in this paper to

Table 2. Specifications of Target PMSM.

\begin{tabular}{lc}
\hline \multicolumn{1}{c}{ Parameter } & Value \\
\hline Rated output power $[\mathrm{kW}]$ & 30 \\
Rated operating speed $[\mathrm{rpm}]$ & 3500 \\
Rated input voltage $\left[\mathrm{V}_{\mathrm{max}}\right]$ & 148.5 \\
Number of slots & 48 \\
Number of poles & 8 \\
Number of turns in series & 20 \\
Number of parallel branches & 8 \\
Stack length [mm] & 140 \\
Core material & $\mathrm{S} 18$ \\
Permanent magnet & $\mathrm{NdFeB} \mathrm{35EH}$ \\
\hline
\end{tabular}

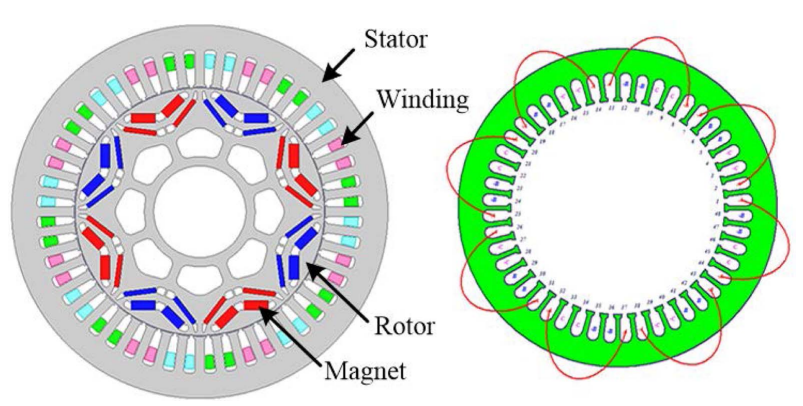

Fig. 1. (Color online) 2D FEA model and winding diagram of target PMSM.

diagnose the faults concerning PM's demagnetization and turn short in PMSM. In the conventional diagnosis method, the rotation of rotor is required to measure BEMF or estimate the motor parameters of driving condition.

On the contrary, in the proposed method, the rotor is kept at standstill condition and the small value high frequency rotating magnetic field of stator is rotated around the locked rotor. HFLV excitation is used to make small value high frequency rotating field of stator.

The HFLV can be made by the power train motor's own drive inverter or another inverter circuit of diagnosis equipment. Figure 2 shows the concept diagram of HFLV injection method.

Where, $V_{m}$ is the maximum input voltage, $\omega_{e}$ is angular speed of rotating magnetic field, $f_{e}$ is frequency of input voltage, $\omega_{r}$ is angular speed of rotor, respectively.

In this diagnosis method, the HFLV is injected to stator winding and the current waveform of each phase is measured. And then, the frequency characteristics of the measured current waveforms are analyzed to diagnose the faults of PMSM. If there are electrical faults such as rotor PM's demagnetization fault and winding turn's fault, the stator current waveform will be changed by the effects of those.

In order to prevent the electrical faults through this proposed diagnosis method, input voltage magnitude is set as under 2[\%] of rated voltage, and the frequency is

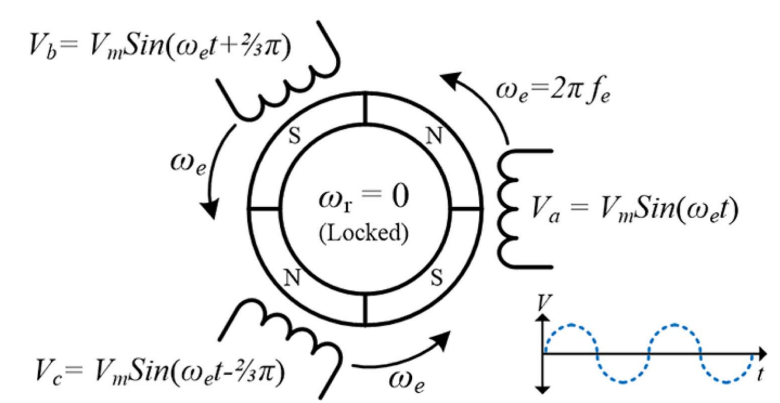

Fig. 2. (Color online) Proposed HFLV injection method. 


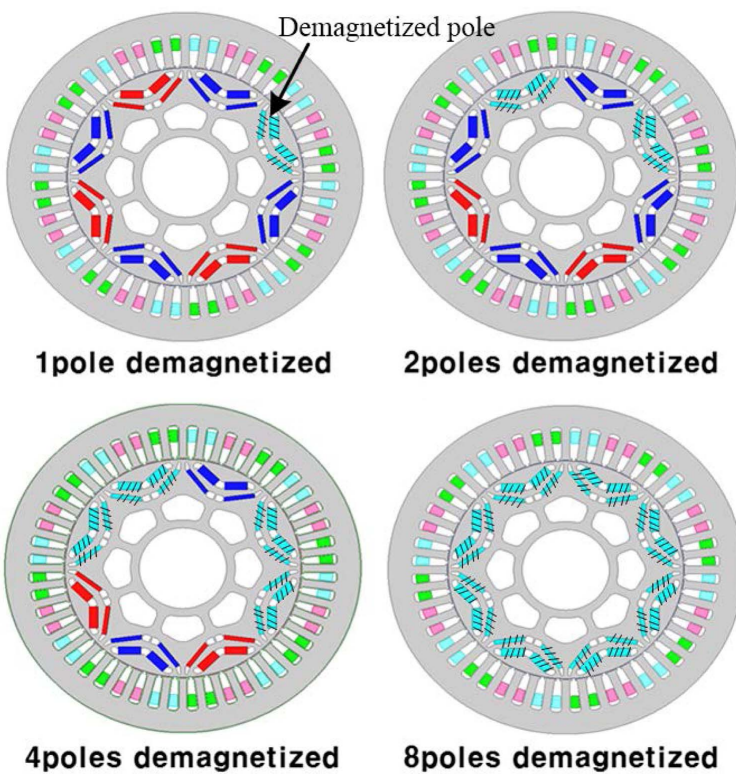

Fig. 3. (Color online) Demagnetization fault analysis models of target PMSM.

set as higher than 6 times of rated frequency. In this study, $f_{e}$ is set as $1.4[\mathrm{kHz}]$ and $V_{m}$ is set as $5[\mathrm{~V}]$ for the proposed diagnosis method.

The current waveform corresponding to rotating magnetic field is influenced by rotor flux distribution. If there is demagnetization fault of PMs, it makes unbalanced and non-uniform flux distribution of rotor.
It can bring about the change of waveform and frequency characteristics of the stator phase currents by HFLV injection to phase windings. For this reason, the demagnetization fault of rotor PM can be diagnosed by using the proposed HFLV injection method.

Figure 3 shows the demagnetization fault analysis models of the target IPMSM, and the demagnetized PMs are indicated by hatching. The demagnetized PMs are arranged arbitrarily to represent various demagnetization fault conditions.

In this paper, it is assumed that the demagnetized PM has $70 \%$ reduced coercive force and residual magnetic flux density.

The example of winding turn's faults is shown in Figure 4. Fault current, the sum of three phase currents, is applied to diagnose the winding turn's fault. The fault current can be calculated by (1)

$$
i_{a}+i_{b}+i_{c}=i_{f}
$$

Where, $i_{a}, i_{b}$ and $i_{c}$ are current of each phase, respectively, and $i_{f}$ is fault current.

When the stator winding is in normal condition, the fault current is always zero. If turn fault is occurred as shown in Fig. 4, the fault current is increased in proportion to the number of faulted turns.

Figure 5 shows 2D FEA model and circuit diagram of turn fault modeling and analysis. Turn fault between same phase winding turns is considered in this model. It is the
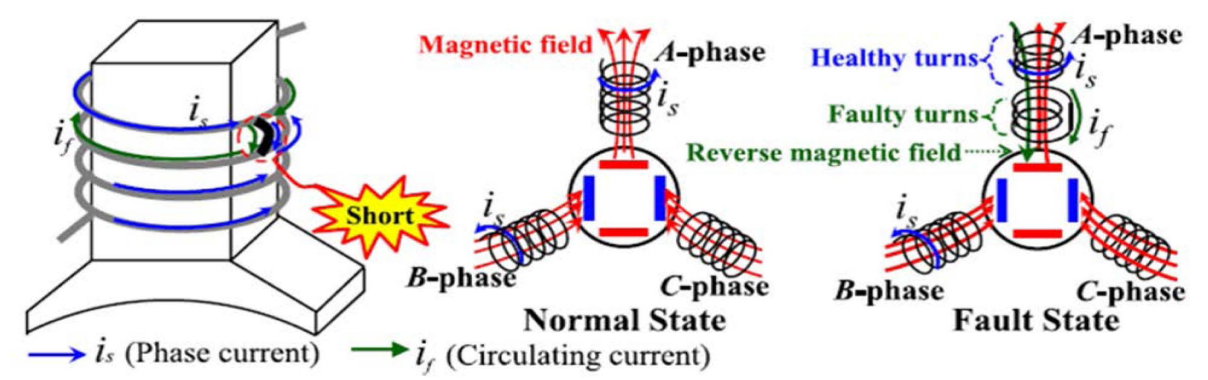

Fig. 4. (Color online) Example diagram of winding turn's fault.
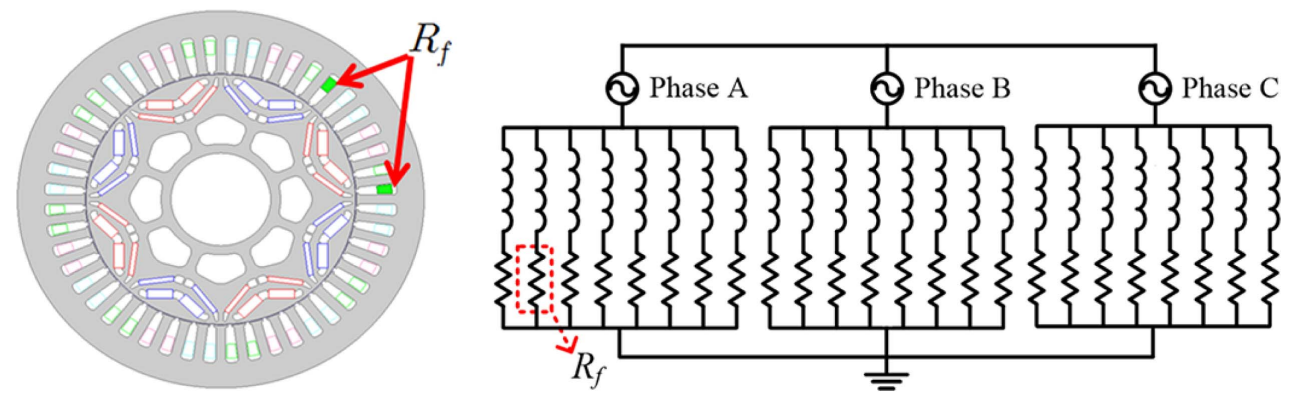

Fig. 5. (Color online) Position of turn fault and circuit diagram for turn fault modeling. 
slightest turn fault case and also the beginning of turn fault progress.

When turn fault is occurred, phase resistance of that coil are assumed as in (2)

$$
R_{f}=R_{s}\left(1-\frac{N_{f}}{N_{t}}\right)
$$

Where, $R_{s}$ is the phase resistance at the normal condition, $R_{f}$ is the phase resistance at turn fault condition, $N_{t}$ is the turn number of coil and $N_{f}$ is the number of faulted turns those are shorted.

In the proposed diagnosis method using HFLV injection to phase winding, the demagnetization fault of PM can be detected by the frequency analysis of phase current, and the turn fault can be detected by the fault current calculation and analysis.

\section{Demagnetization Fault and Turn Fault Analysis Results}

The proposed HFLV injection diagnosis method is applied for the target PMSM to diagnose each demagnetization fault model in Fig. 3. The phase current waveform of each demagnetization fault model is shown in Fig. 6.

As shown in Fig. 6, the magnitude of phase current of each PM demagnetized models are significantly decreased to $20[\%]$ of normal condition.

It is due to rotor flux distribution characteristics. When there is no demagnetized rotor pole, the fluxes from rotor
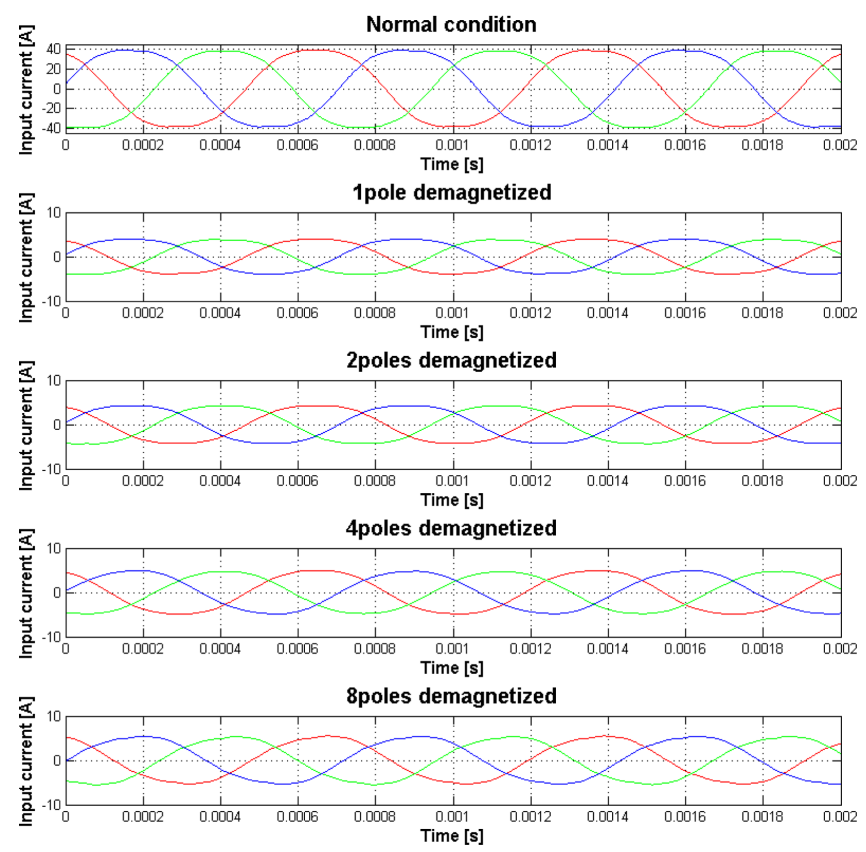

Fig. 6. (Color online) Input current waveform of demagnetization fault models.
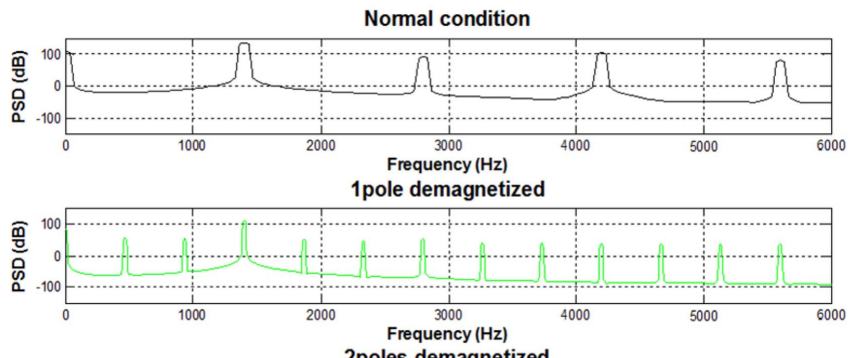

2poles demagnetized

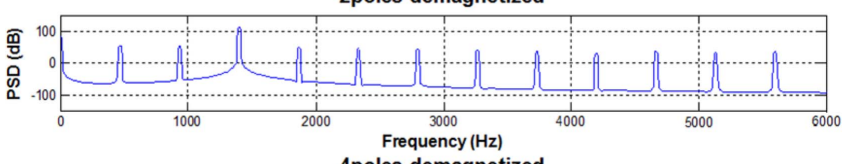
4poles demagnetized
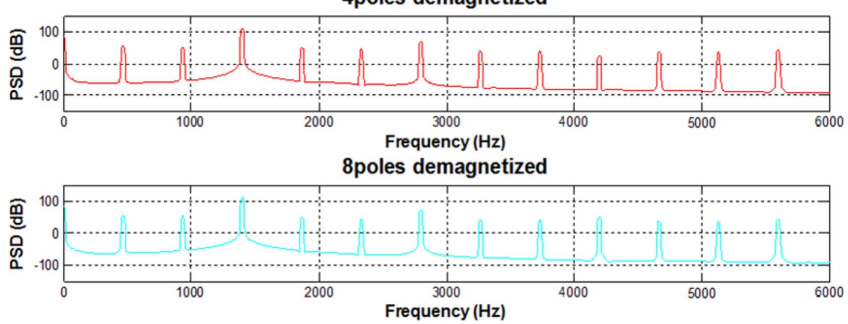

Fig. 7. (Color online) Frequency analysis results of demagnetization fault models.

PM is distributed uniformly. These fluxes block the high frequency rotating field of stator winding, and it causes the increase of stator phase current magnitude.

If there are demagnetized PMs in the rotor, it may result in inductance variation in the rotor magnet circuit. This inductance variation may reduce the magnitude of stator phase current.

In addition, stator currents in Fig. 6 are analyzed using FFT as shown in Fig. 7. Where, power spectral density (PSD) indicates the variation of a signal's power versus frequency.

As shown in Fig. 7, fundamental and n-th order harmonic components of the HFLV are shown in FFT analysis results when there is no demagnetization fault in rotor PMs. On the other hand, if there were demagnetization fault of PMs in rotor, additional components are observed which were not shown in normal condition.

Based on the time and frequency domain diagnosis results using HFLV injection method in Fig. 6 and Fig. 7, the demagnetization fault of PM can be detected.

The HFLV injection diagnosis method is also applied for the target PMSM to diagnose each the turn faults models shown in Fig. 5. In this figure, 'n turns fault' means that $n$ turns are shorted. When there are turn faults in the stator winding turns and no demagnetization fault of rotor PMs, unbalanced phase current waveforms are presented as seen in Fig. 8.

The stator current waveform of faulted phase is analyzed 

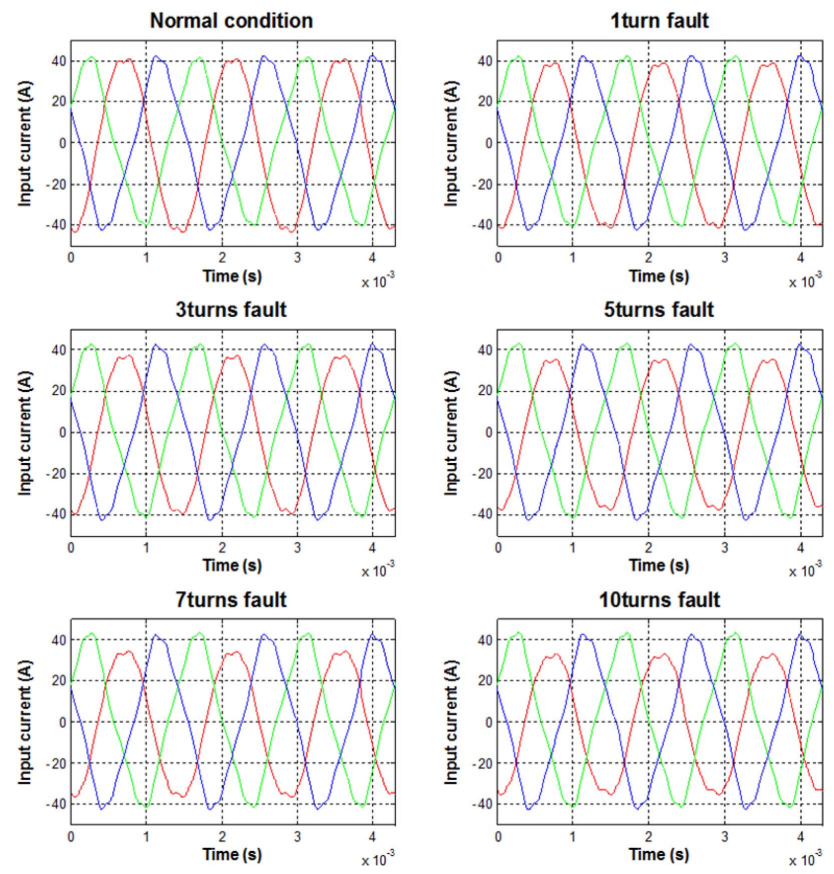

Fig. 8. (Color online) Input current waveform of turn fault models.
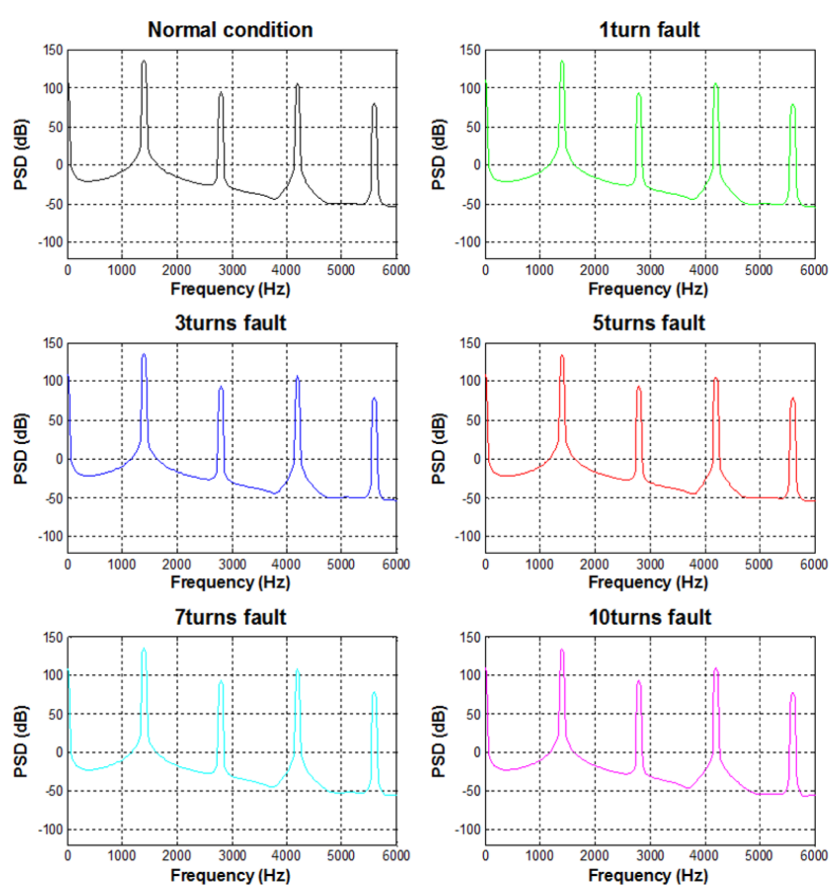

Fig. 9. (Color online) Frequency analysis results of turn fault models.

using FFT as shown in Fig. 9. Even though there are turn faults in the winding, the frequency domain characteristics are almost similar to each other regardless of fault turn numbers. It means that the turn faults give no effect on the frequency domain characteristics of stator phase
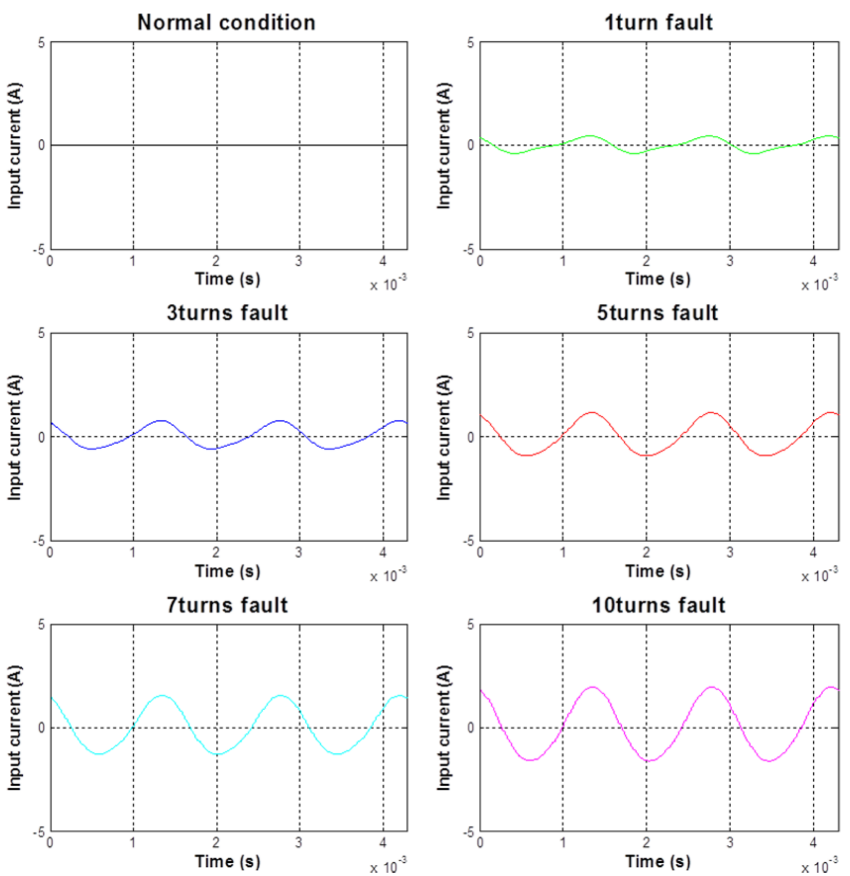

Fig. 10. (Color online) Fault current of turn fault models.
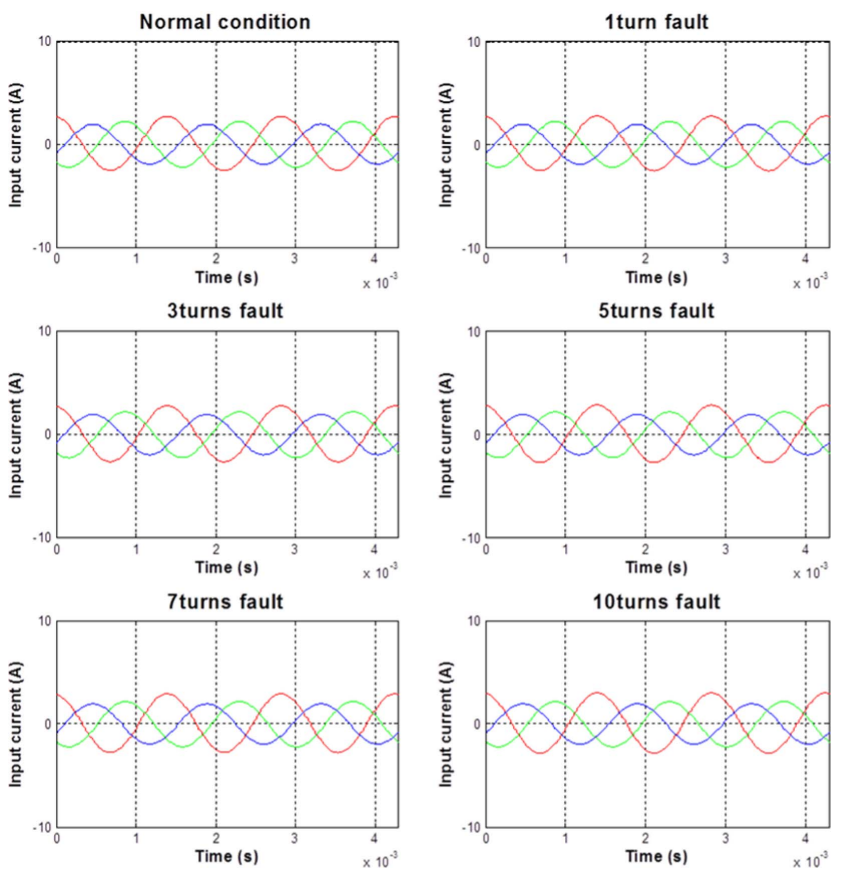

Fig. 11. (Color online) Stator current waveforms of demagnetization and turn fault models.

current.

Fault current is calculated using each phase current of Fig. 8 and (1), and it is presented in in Fig. 10. The fault current is increased as the number of faulted turns is increased.

Therefore, the proposed HFLV injection method is useful 

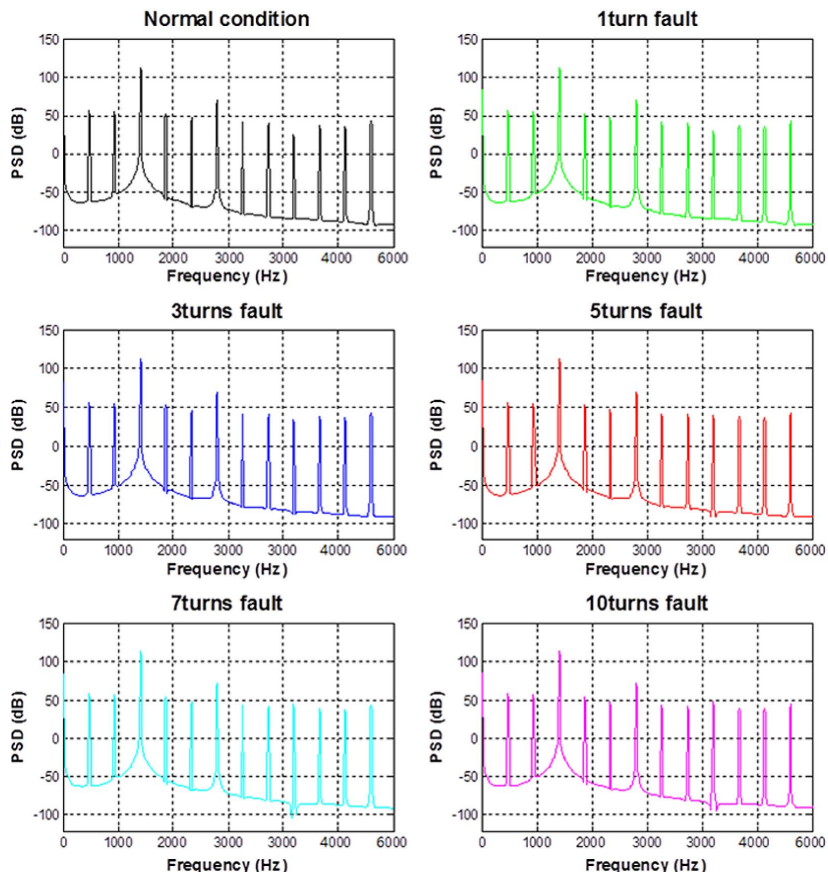

Fig. 12. (Color online) Frequency analysis results of demagnetization and turn fault models.

to diagnose winding turn's faults by calculating fault currents.

The proposed method is applied for fault motors having demagnetization fault of PM and turn fault together. In this study, it is assumed that PM of one pole is demagnetized.

The instantaneous current waveforms of this case are similar to that of Fig. 6 as shown in Fig. 11. The magnitude of phase current is very small compared with normal condition without demagnetization fault of PM.

In addition, stator phase currents of Fig. 11 are analyzed using FFT as shown in Fig. 12. As previously mentioned, the frequency domain characteristics are almost same to that of Fig. 7 and 12 representing the faults of PM demagnetization.

Therefore, the FFT analysis of stator phase current generated by HFLV injection method is useful to detect the demagnetization fault of rotor PM even if there are winding turn's fault. Fault current is calculated using each phase current of Fig. 11 and (1), and it is presented in Fig. 13. The fault current is increased as the number of faulted turns is increased as previously mentioned in turn fault result.

As results, the proposed HFLV injection method is useful to diagnose winding turn's faults by calculating fault currents even if there are demagnetization fault of PM. In other words, the proposed HFLV injection method can be applied for independent faults diagnosis of demag-
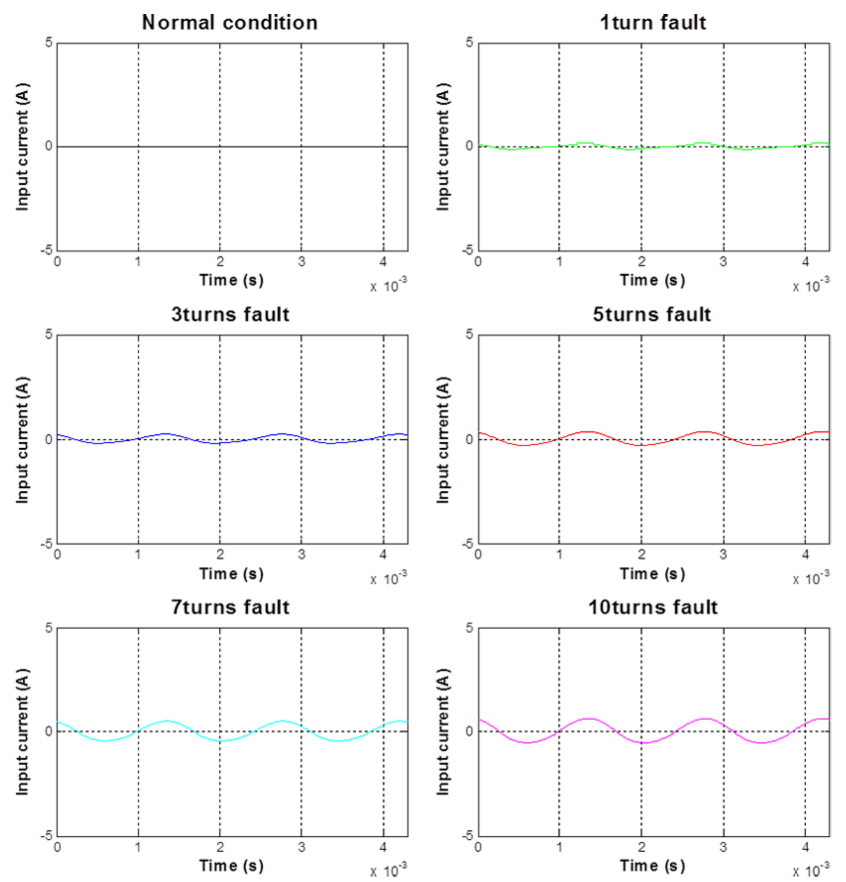

Fig. 13. (Color online) Fault current of demagnetization and turn fault models.

netization fault of PM and winding turn's faults.

\section{Conclusion}

In this paper, the fault diagnosis method using high frequency low voltage injection method is proposed to diagnose demagnetization fault of rotor PM and turn fault of stator winding.

The proposed method detects demagnetization fault based on the frequency analysis results of input current waveform. On the other hand, turn fault can be detected by calculating the fault current of stator phase currents.

The feasibility and usefulness of the proposed fault diagnosis method was verified by the FE analysis. The proposed method can be used to check the faults of PMSM during system check-up process at vehicle starting and idling stop mode.

\section{Acknowledgments}

This work was supported by the Kyungnam University Foundation Grant, 2014.

\section{References}

[1] J. R. Riba, A. Garcia, and L. Romeral, Electric Power System Res. 80, 10 (2010).

[2] J. R. Riba, J. A. Rosero, A. Garcia, and L. Romeral, 
IEEE Trans. Magn. 45, 7 (2009).

[3] R. A. Gupta, A. K. Wadhwani, and S. R. Kapoor, IEEE Trans. Energy Conversion 26, 1 (2011).

[4] M. A. Cash, T. G. Habetler, and G. B. Kliman, IEEE Trans. Ind. Appl. 34, 6 (1998).

[5] F. Briz, M. W. Degner, P. Garcia, and A. B. Diez, IEEE
Trans. Ind. Electron. 55, 12 (2008).

[6] K. C. Kim, S. B. Lim, D. H. Koo, and J. Lee, IEEE Trans. Magn. 42, 10 (2006).

[7] Y. Huangfu, W. Liu, and R. Ma, 3rd IEEE Conference on Industrial Electronics and Applications (ICIEA), (2008). 